SCIENTIFIC REPORT

\title{
Progressive restrictive strabismus acquired in infancy
}

\author{
C Souza-Dias, A B Scott, A-H Wang
}

Br J Ophthalmol 2005;89:986-987. doi: 10.1136/bjo.2004.058545

The authors present three cases of severely restricted motility and large angle strabismus acquired rapidly during the first months of life in otherwise normal children who had normal eye alignment and movements at birth. Surgical treatment of these cases is difficult and outcomes are variable. Myositis causing extraocular muscles fibrosis is a possible cause of the strabismus in these cases.

$\mathrm{R}$ estrictive strabismus in infancy is not rare. Congenital extraocular muscle fibrosis ${ }^{1}$ and abnormal bands and tendon restriction, sometimes associated with other body or ocular anomalies, are well documented..$^{2-7}$ We report here three cases of large angle restrictive unilateral strabismus developing over a period of a few months in infancy in otherwise normal children documented to have normal eye alignment and motility as newborns. Some findings are suggestive of inflammation as the cause of the strabismus.

\section{CASE REPORTS}

\section{Case 1}

Case 1 was a male child who had normal gestation and birth. There is no family history of strabismus. Normal eye alignment and movements were present until 2 months of age (fig 1). Then, the right eye started to deviate medially and downward without proptosis, redness of the eye, or associated illness. At 4 months of age, the eye position stabilised in 50 degrees of esotropia and 30 degrees of hypotropia. Magnetic resonance imaging examination (MRI) showed fuzziness around the medial and inferior rectus muscles, which was interpreted by the radiologist as typical of myositis. There was no alignment change after a trial of systemic prednisone at 4 months. Surgery at 4 months of age and again 2 weeks later did not succeed in hooking the medial and inferior rectus muscles. An MRI scan at 6 months of age showed only the enlargement of the medial and inferior muscles expected with marked rotation of the eye into their field of action. At surgery at 6 months of age, the medial and inferior rectus muscles restrained any passive globe rotation into abduction or elevation. A small dental mirror allowed visualisation of the tendons, which could not be visualised directly. After these were clamped and detached from the globe, the eye rotated freely. Each muscle was recessed $10 \mathrm{~mm}$ on adjustable sutures. The eye was exotropic on the next day, and the medial rectus suture was tightened $3 \mathrm{~mm}$. The left eye was patched for amblyopia. At 4 years of age there was an esotropia of 20 prism dioptres with mild limitation of adduction and infraduction. At 11 years of age the right eye had become more esotropic, perhaps as a result of amblyopia. Vision was 20/60 in the right eye 20/20 in the left.

\section{Case 2}

Case 2 was a male child with normal gestation and birth and no family history of strabismus. Normal eye and lid movements were reported until 4 months of age, when the right eye developed increasing hypertropia (fig 2) finally stabilising at age 7 months. At age 8 months, right hypertropia of about 45 degrees was observed, with the cornea barely visible underneath the superior eyelid. Computed tomography (CT) scan showed an enlarged superior rectus. Serological tests for Graves' disease were normal. At surgery at 8 months of age, the right eye could not be passively infraducted. A blind free tenotomy of the superior rectus muscle released the restriction to infraduction. Eight months after the operation, orthotropia was observed except in supraversion where there was a small right hypotropia. Intraocular structures and refraction were normal. Vision was equal in the two eyes with central fixation in each eye.

\section{Case 3}

Case 3 was a female child with normal eyes and health at birth. No family history of strabismus. Family photographs

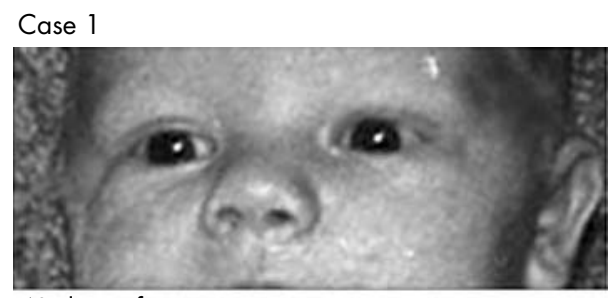

42 days of age

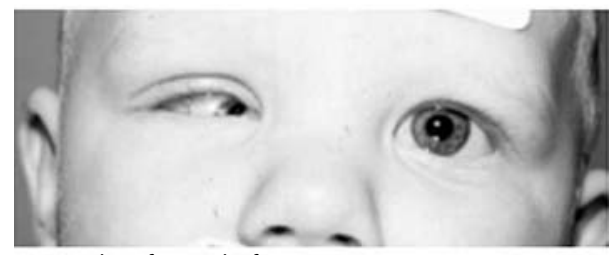

6 months of age, before surgery

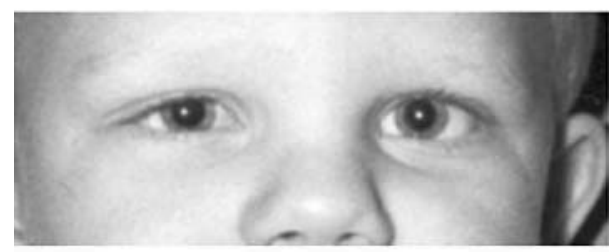

4 years of age

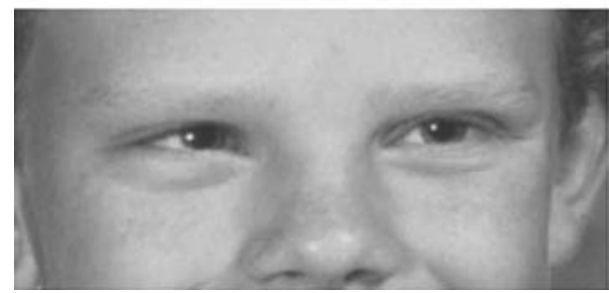

11 years of age

Figure 1 Case 1. 


\section{Case 2}

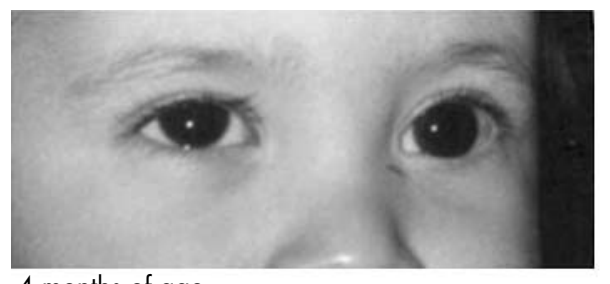

4 months of age

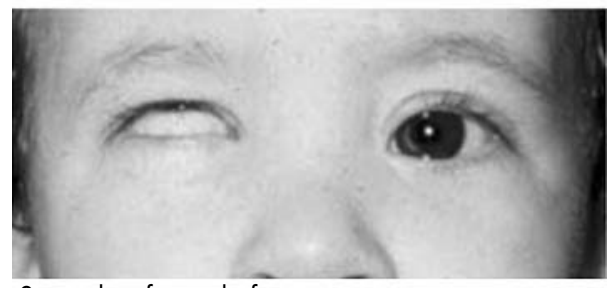

8 months of age, before surgery

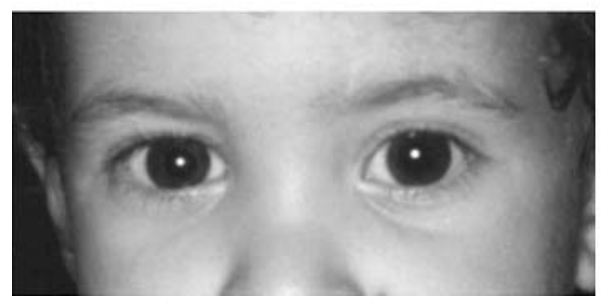

16 months of age, 8 months after surgery

Figure 2 Case 2.

document normal eye alignment and appearance at 1 month of age. At 3 months, the parents observed a right esotropia, which progressed to 40-50 degrees esotropia and 4050 degrees of hypotropia at the time of examination at age 4 months. There was no history of trauma. CT and MRI scans showed enlarged right medial and inferior rectus muscles. Passive ductions showed total limitation of elevation and abduction. Biopsy of a right thigh muscle was normal. At surgery at 5 months of age, the inferior rectus was red and swollen. The medial rectus and inferior rectus muscles were recessed. A second operation removing adhesions and using traction sutures did not eliminate the hypotropia. Postoperatively, the eye remained hypotropic, exotropic, and amblyopic.

\section{DISCUSSION}

An earlier report by Palolillo and others ${ }^{8}$ details a similar case history of initial normality with onset of progressive hypotropia at 2 months of age. When the thin taut inferior rectus muscle was surgically severed at 4 months of age, the restriction was freed. However, the postoperative result was poor, with exotropia and limited infraduction. This case and our three cases showed no abnormality in function of the other extraocular muscles of the involved eye or of the fellow eye at any time, making progressive ophthalmolplegia an unlikely cause. In a series of 83 children with Graves' disease, only one showed restricted motility and that was of mild degree, making this, also, an unlikely cause in these cases. ${ }^{9} \mathrm{~A}$ few reports give hints of inflammation as a cause of infantile strabismus. A unilateral case of inferior rectus fibrosis reported by Prieto-Diaz and Laguens, ${ }^{10}$ showed mitochondria alterations, which may be the sequel of a previous myositis. Harley et $a l^{11}$ and Leone et al ${ }^{12}$ suggested prenatal inflammatory origin as a possible cause of congenital unilateral restrictive cases. The progressive course, image examination findings, and surgical findings suggest subacute myositis as a possible cause of these cases. While the inflammation of acute myositis in adults is characterised by pain, subacute cases occur without such severe pain. Myositis often responds well to steroid drug treatment. While empirical use of prednisone did not help in case 1 , this was not instituted until age 4 months when restriction had already become established. Used early, steroids might avert the large angle strabismus in future cases like these. Acquired strabismus in infancy occurring together with acute redness, pain, or proptosis is characteristic of orbital infection, bleeding, or rapid tumour growth, and should be differentiated from these cases. ${ }^{13}$ Understanding of these cases is fragmentary, and vigorous exploration of any new and early cases by MRI and laboratory techniques is indicated.

\section{Authors' affiliations}

C Souza-Dias, Faculty of Medical Sciences, Santa Casa de Sao Paulo, Department of Ophthalmology, Sao Paulo, Brazil

A B Scott, Smith-Kettlewell Eye Research Institute, San Francisco, CA, USA

A-H Wang, National Taiwan University Hospital, Taipei, Taiwan

Supported in part by Pacific Vision Foundation, San Francisco, CA, USA.

Correspondence to: Carlos Souza-Dias, MD, Rua Cincinato Braga, 59, ci 5 B2, 01333-011, Sao Paulo, SP, Brazil; csdias@uol.com.br

Accepted for publication 2 February 2005

\section{REFERENCES}

1 Baumgarten M, Jaafar MS, Traboulsi El. Congenital fibrosis of the extraocular muscles. In: Rosembaum AL, Santiago AP, eds. Clinical strabismus management. Philadelphia: WB Saunders, 1999:363.

2 Brown HW. Congenital structural muscle anomalies. In: Allen JH, ed. Symposium on strabismus. Transactions of the New Orleans Academy of Ophthalmology. St Louis: CV Mosby, 1950:205.

3 Appleton RE, Chitayat D, Jan JE, et al. Joubert's syndrome associated with congenital ocular fibrosis and histidinemia. Arch Neurol 1989:46:579.

4 Brodsky MC, Pollok SC, Buckley EG. Neural misdirection in congenital ocular fibrosis syndrome. J Pediatr Ophthalmol Strabismus 1989;26:159-61.

5 Prieto-Diaz J, Souza-Dias C. Strabismus, 4th ed. Boston: Butterworth Heinemann, 2000:435-6.

6 Weiss A, Manley D. Congenital tight superior rectus muscle. J Pediatr Ophthalmol Strabismus 1985;22:51-3.

7 Engle E. A genetic approach to congenital extraocular muscles disorders. J Child Neuro 1999;14:34-7.

8 Paolillo RD, Burch PG, Torchia RT. Infantile contracture of inferior rectus muscle with resultant mechanical hypotropia. Am J Ophthalmol 1969:68:1057-60.

9 Chan W, Wong GW, Fan DS, et al. Ophthalmopathy in childhood Graves' disease. Br J Ophthalmol 2002;86:740-2.

10 Prieto-Diaz J, Laguens R. Fibrosis congenital del recto inferior. Estudio clinico ultraestructural. Arch Oftalmol B Aires 1973;48:301-12.

11 Harley RD, Rodrigues MM, Crawford JS. Congenital fibrosis of the extraocular muscles. J Pediatr Ophthalmol Strabismus 1978;15:346-58.

12 Leone CR Jr, Weinstein GW. Orbital fibrosis with enophthalmos. Ophthalmic Surg 1972;3:71-5.

13 Jain S, Goulstine D, Gottlob I. Acute adduction deficit in a 7-week-old infant. Strabismus 2002;10:241-4. 